Portland State University

PDXScholar

5-4-1993

\title{
Sentence Discrimination in Noise and Self-assessed Hearing Difficulty
}

Dianna W. Brainerd

Portland State University

Follow this and additional works at: https://pdxscholar.library.pdx.edu/open_access_etds

Part of the Other Communication Commons, and the Speech and Rhetorical Studies Commons Let us know how access to this document benefits you.

\section{Recommended Citation}

Brainerd, Dianna W., "Sentence Discrimination in Noise and Self-assessed Hearing Difficulty" (1993). Dissertations and Theses. Paper 4523.

https://doi.org/10.15760/etd.6407

This Thesis is brought to you for free and open access. It has been accepted for inclusion in Dissertations and Theses by an authorized administrator of PDXScholar. Please contact us if we can make this document more accessible: pdxscholar@pdx.edu. 
AN ABSTRACT OF THE THESIS OF Dianna $W$. Brainerd for the Master of Science in Speech Communication: Speech and Hearing Sciences presented May 4, 1993.

Title: Sentence Discrimination in Noise and Self-Assessed Hearing Difficulty

APPROVED BY MEMBERS OF THE THESIS COMMITTEE:

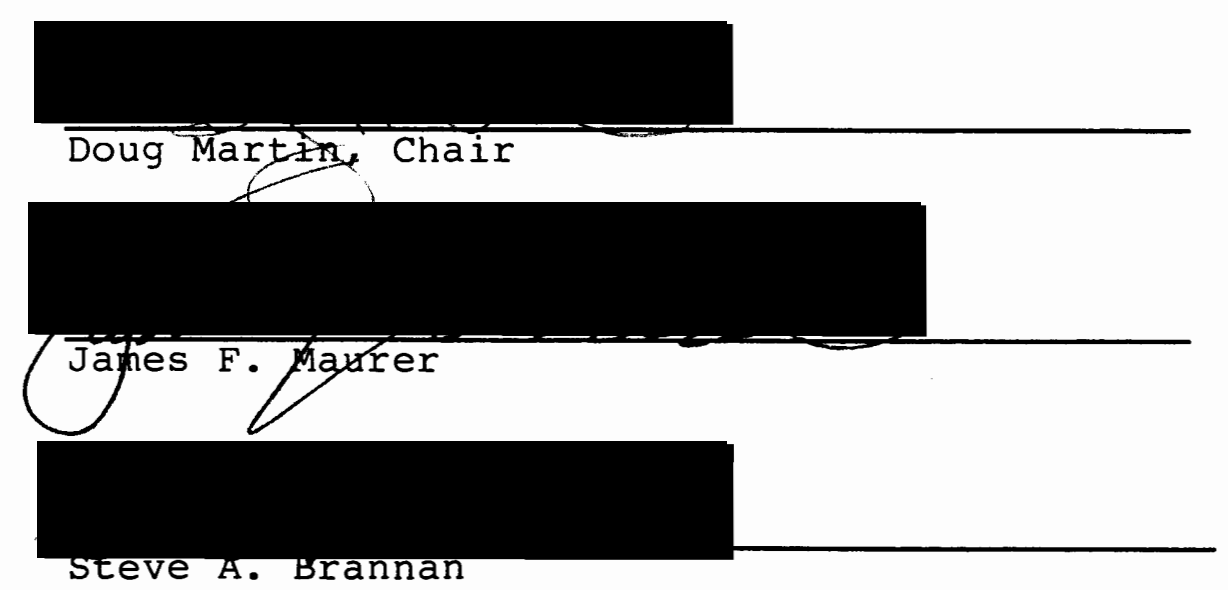

The purpose of the study was to evaluate the sensitivity of the CID Everyday sentences, with competing cafeteria noise, as a measure of the real life receptive communication difficulty experienced by subjects with 
hearing loss limited to frequencies above $2000 \mathrm{~Hz}$. In order to establish normative data the speech discrimination test was given to 38 normal hearing subjects (aged 19-46). Second, the discrimination test was given to 12 hearing impaired subjects (29-64), who also completed a self-assessment questionnaire, the Hearing Handicap Inventory for Adults (HHIA). The results were analyzed to determine: (a) if there was a significant difference between the mean scores of the normal hearing and the hearing impaired subjects, and (b) if there was a significant correlation between the hearing impaired subjects' scores on the discrimination test and those obtained on the HHIA.

The investigation revealed that a statistically significant difference $(p=0.04)$ existed between the mean scores of the two subject groups on the discrimination test. The hearing impaired subjects averaged about $9 \%$ below the normal hearing subjects. Although there was a weak to moderate correlation between the hearing impaired subjects' scores on the discrimination test and their scores on the HHIA, it was not statistically significant.

It was concluded that, with further research, the CID Everyday sentences, with competing cafeteria noise, have potential merit as a speech discrimination procedure to quantify the hearing handicap produced by a high frequency hearing loss. 


\title{
SENTENCE DISCRIMINATION IN NOISE
}

AND SELF-ASSESSED HEARING DIFFICULTY

by

DIANNA W. BRAINERD A thesis submitted in partial fulfillment of the
requirements for the degree of

\author{
MASTER OF SCIENCE \\ in \\ SPEECH COMMUNICATION : \\ SPEECH AND HEARING SCIENCES
}

Portland State University

1993 
TO THE OFFICE OF GRADUATE STUDIES AND RESEARCH:

The members of the Committee approve the thesis

of Dianna W. Brainerd presented on May 4, 1993.

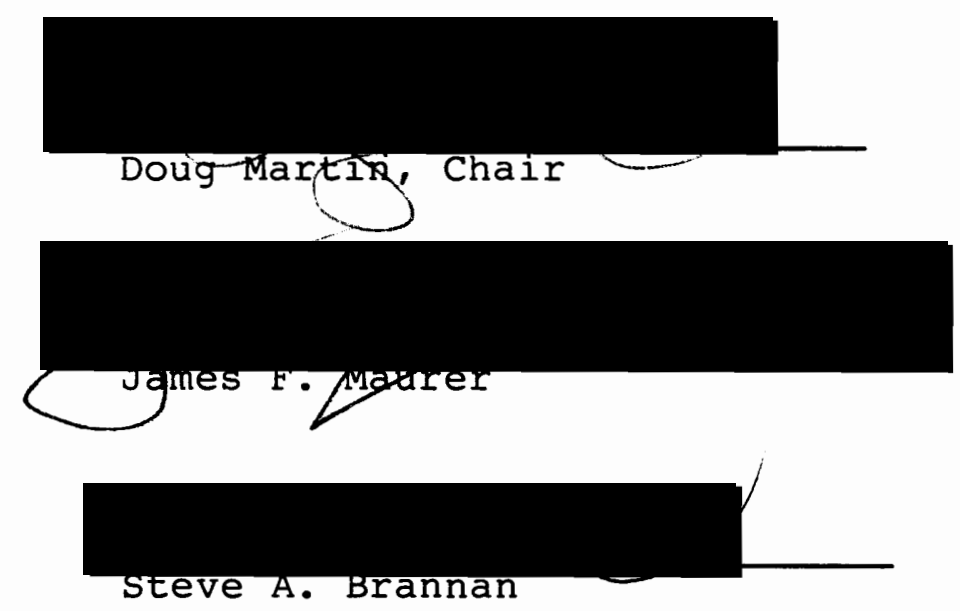

APPROVED :
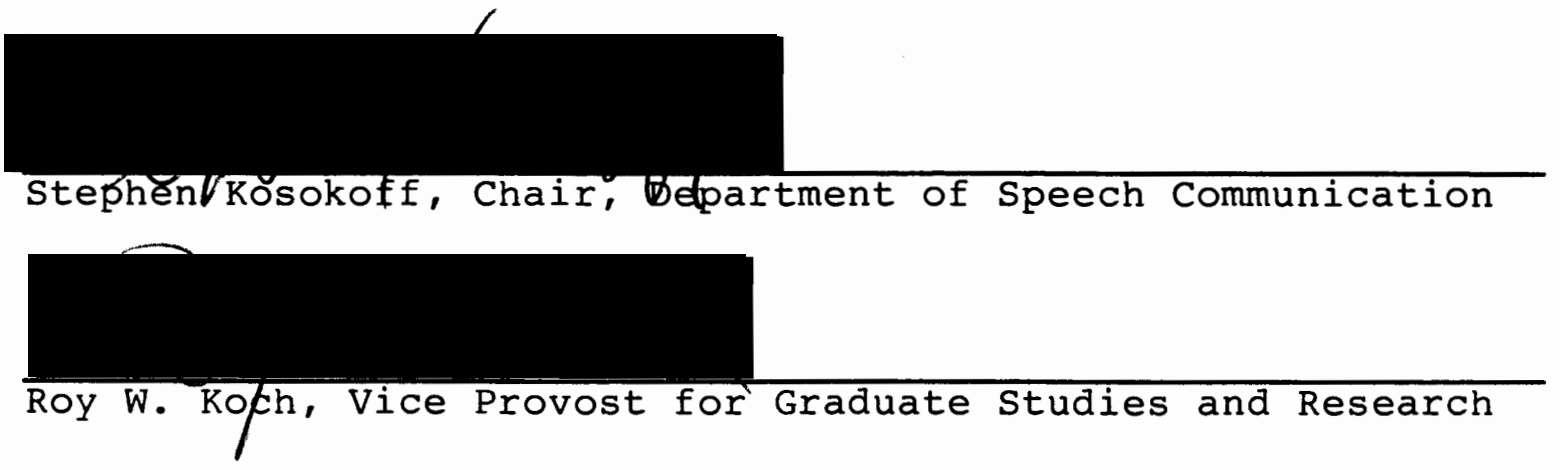
THIS THESIS IS DEDICATED TO MY PARENTS

BOB AND HELEN JOHNSON 


\section{ACKNOWLEDGEMENTS}

I am greatly indebted to Dr. James F. Maurer who graciously continued his invaluable direction and support for this study following his retirement.

My gratitude goes to $\mathrm{Dr}$. Doug Martin who became my advisor and chairman of my thesis committee following the start of this investigation. His positive attitude and readiness to help were greatly appreciated.

I would like to thank Dr. Steve Brannan for serving on my thesis committee and providing key suggestions which served to clarify my thinking and writing.

My thanks go to John Coverstone for his time and expertise in preparing the audio tapes used in the study.

I would also like to thank Barry Edwards for his analysis of the data and for his patient explanations. Finally, my special gratitude and appreciation go to Emily P. Maulsby. Although she did not advise on the content of this thesis, she has been an invaluable source of support, encouragement, and advice throughout the thesis process, as well as my entire graduate education. 
TABLE OF CONTENTS

PAGE

ACKNOWLEDGEMENTS........................ iii

LIST OF TABLES........................ vi

LIST OF FIGURES......................... vii

CHAPTER

I INTRODUCTION...................

Purpose.................... 3

II REVIEW OF THE LITERATURE........... 5

Speech Discrimination in Noise... 5

Self-assessment scales......... 7

CID Everyday Speech Sentences.... 8

III METHODS..................... II

subjects...................11

Normal Hearing Subjects...... I1

Hearing Impaired Subjects.... 12

Materials................. 13

Instrumentation............. 14

Procedures.................. 14

Normal Hearing Subjects...... 14

Hearing Impaired subjects.... 15 


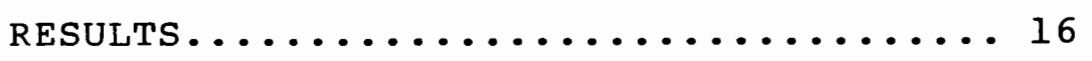

V DISCUSSIONS AND CONCLUSIONS.......... 24

Implications for Further Research 26

Conclusions................ 27

REFERENCES........................ 28

APPENDICES

A HHIA Self-Assessment Questionnaire.. 30

B CID Everyday Speech Sentences...... 33

C Subject Instructions............ 35 


\section{LIST OF TABLES}

TABLE

PAGE

I Raw Performance Data for Normal Hearing

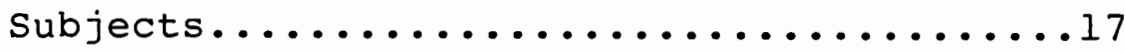

I Summary of Performance Data of Normal Hearing

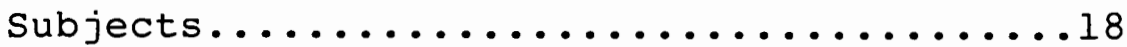

III Raw Performance Data for Hearing Impaired

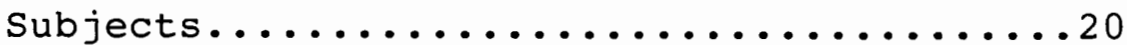

IV Comparison of Summarized Performance Data for Both Groups of subjects..............21 


\section{LIST OF FIGURES}

FIGURE

PAGE

1. Box Plot of Discrimination Scores for All

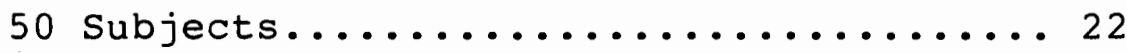

2. Plot of Residuals Vs Fits for Hearing

Impaired subjects................. 22 


\section{CHAPTER I}

\section{INTRODUCTION}

Speech represents the class of sounds most important in the daily functioning of human beings (Olsen \& Matkin, 1979). The ability to recognize differences in speech sounds is the first step in the complex process of perception, conception, and classification of information (stockdell, 1980). Thus measures of speech discrimination are a fundamental component of the audiological evaluation. The standard audiological test battery includes a supra-threshold measure of speech discrimination, using a monosyllabic word list, presented in quiet, as the stimulus.

Audiologists frequently see clients with relatively normal pure tone thresholds ( $25 \mathrm{~dB} \mathrm{HL}$ or less) at test frequencies of $2000 \mathrm{~Hz}$ and below, but with elevated thresholds in the higher frequencies. Typically, these clients report little receptive communication difficulty in quiet environments, but increased difficulty hearing in situations where background noise is present. For this population, scores on a standard word discrimination test in quiet are often in the range of 90-100\%, which is considered normal discrimination ability. Thus, the 
standard measure used to assess speech discrimination does not reflect the real life problem reported by the client with a high frequency hearing loss, which is understanding speech in background noise. Rather, it seems to reflect the ability to discriminate speech in quiet environments where the client reports no difficulty at all.

For years the standard monosyllabic word discrimination test has been criticized for not reflecting a discrimination task that is representative of everyday speech (olsen \& Matkin, 1979). It is phrases or sentences, rather than single words, which are the content of everyday speech in which listeners must discriminate sounds and interpret meanings. Additionally, human communication is rarely carried on in a totally quiet environment. Instead communication is most often conducted in environments where there is competing background noise, such as other people talking and/or the interference of ambient non-conversational sound.

Although there is speculation among audiologists that a sentence test in noise may be a more sensitive measure of a client's difficulty hearing in everyday situations, there is currently no standardized sentence test which is suitable for clinical use (Olsen \& Matkin, 1979). The only standardized sentence test in noise is the Speech Perception in Noise (SPIN) test (Kalikow \& Stevens, 1977) which is currently used for research 
purposes. However, due to its length it is considered impractical by many clinicians.

The CID Everyday sentences, combined with noise, are reportedly used informally by some clinicians with good results (Garstecki, 1980). The CID Everyday sentences were an early attempt to construct sentences for use in speech discrimination assessment. Although these sentences have been available for many years they have never been developed into a standardized test and have not received widespread use (Davis \& Silverman, 1978; Silverman \& Hirsh, 1955).

PURPOSE

The purpose of the current study was to evaluate the sensitivity of the CID Everyday sentences, with competing cafeteria noise, as a measure of the real life communication difficulty experienced by the listener. To accomplish this, the CID Everyday sentences in competing cafeteria noise were first administered to thirty-eight normal hearing subjects, aged 19-46, for the purpose of establishing normative data. Second, twelve subjects, aged 29-64, all exhibiting high frequency sensorineural hearing losses, were selected as subjects. These subjects were administered the CID Everyday sentences presented with competing cafeteria noise. In addition, they were 
administered a self-assessment questionnaire, the Hearing Handicap Inventory for Adults (HHIA). The scores on the questionnaire, which was considered a reliable measure of real life hearing handicap, were compared to those obtained on the discrimination test for the purpose of further validating the discrimination test. Statistical analysis was conducted to determine: (a) if the hearing impaired subjects' scores were significantly different from those of the normal hearing subjects, and (b) if a significant correlation existed between the two measures administered to the hearing impaired subjects. 
CHAPTER II

REVIEW OF THE LITERATURE

SPEECH DISCRIMINATION IN NOISE

Abel, Krever, and Alberti (1990), using 73 adult subjects, studied the changes that occurred in speech discrimination ability in background noise as a result of aging and bilateral sensorineural hearing loss. The effects of different types of background noise and signal-to-noise ratio were investigated using nine different measures. Of particular interest is the Speech Perception in Noise (SPIN) test result, in which the performance of normal hearing older subjects was not affected by the presence of the masking noise. However, the performance of the subjects with sensorineural hearing loss was significantly reduced and sensitive to the degree of loss. The investigators found that, in individuals with sensorineural hearing loss, pure tone thresholds for 2000 and $4000 \mathrm{~Hz}$ were most related to speech discrimination ability, both in quiet and in noise. Results supported previous research that in individuals with sensorineural 
hearing loss, the presence of background noise is particularly detrimental to understanding speech (Cooper \& Cutts, 1971; Bess \& Townsend, 1977; Suter, 1985).

The effect of noise on word discrimination in normal hearing and hearing-impaired subjects was examined by Pekkarinen, Salmivalli, and Suonpaa (1990). Subjects with sensorineural hearing loss were more adversely affected by noise than subjects with normal hearing or conductive losses. Subjects with elevated hearing thresholds above $2000 \mathrm{~Hz}$ discriminated speech in quiet and in low noise levels as well as normal hearing subjects. However, at high levels of noise, discrimination ability in the hearing impaired was significantly poorer than that of the normal hearing subjects. The investigators also found that as the noise level was increased the intersubject variability increased. Although this was true for all groups, the variability was greater for the sensorineural hearing loss subjects.

Increased variability in the performance of sensorineural hearing-impaired subjects on speech discrimination tasks in noise was also found by cooper \& Cutts (1971) in a study of 31 subjects. The authors suggest that, due to this variability of individual performance in background noise, speech discrimination should routinely be measured in noise, especially in the selection and evaluation of a hearing aid. 


\section{SELF-ASSESSMENT SCALES}

Self-assessment measures of an individual's response to a hearing impairment received renewed interest in the early 1980's due to the fact that audiometric data often fell short of describing the impact of a hearing loss on everyday functioning (Davis \& Hardick, 1981; Giolas, 1982). Ventry \& Weinstein (1982) state that "whereas hearing tests can quantify sensitivity loss, speech hearing difficulty, and the like, they are not well suited to measuring or quantifying the effect of the hearing impairment on a person's everyday function" (p. 128). Thus, it was believed that information provided by self-assessment scales could play an important role in understanding the communication difficulty of hearing-impaired adults and in the management of their rehabilitation (Ventry \& Weinstein, 1982).

The Hearing Handicap Inventory for the Elderly (HHIE) (Ventry \& Weinstein, 1982) represented a technique for measuring the emotional and social/situational effects of hearing impairment on the noninstitutionalized elderly. The HHIE was brief, simple, easily administered and interpreted. Weinstein and Ventry (1983) examined the relationships between pure-tone sensitivity, word recognition, and self-assessment as measured by the Hearing Handicap Inventory for the Elderly (HHIE) in a group of 100 elderly subjects. A significant correlation was 
found between pure-tone sensitivity and the HHIE. Although a significant correlation was also found between speech discrimination measures and the HHIE, it was a weaker correlation than that of the pure-tone measure. The authors believed that this finding, which they expected to be highly correlated to the HHIE, was related to the choice of speech discrimination materials, the standard audiological test battery measure of words in quiet. Weinstein and Ventry therefore concluded that a standard speech discrimination measure added no further insight into hearing handicap than that provided by pure-tone audiometry.

The Hearing Handicap Inventory for the Elderly (HHIE) was modified in 1990 by substituting three questions which were thought to be more appropriate for younger adults. The substituted questions related to occupational effects of hearing loss. This revision, known as the Hearing Handicap Inventory for Adults (HHIA) was standardized on 67 adults ranging from 18-64 years old (Newman, Weinstein, Jacobson, \& Hug, 1990). Results indicated the same high internal consistency reliability found in the HHIE.

\section{CID EVERYDAY SPEECH SENTENCES}

The CID Everyday sentences were originally developed for the purpose of validating existing discrimination 
test materials by Grant Fairbanks and a Working Group of the Armed Forces-National Research Council Committee on Hearing and Bio-Acoustics (Davis \& Silverman, 1978; Silverman \& Hirsch, 1955). The sentences were developed to represent colloquial speech. Giolas (1966) found a close relationship between discrimination scores using selected CID sentences and a sample of continuous discourse. Although, no standardized test has been developed from the sentences (Garstecki, 1980), they have been used clinically for informal evaluation purposes. Widely differing views of the sentences are reported in the literature. Garstecki (1980) reports that the sentences have "high face validity", where Newby and Popelka (1985) report that even when the sentences are presented with competing noise (the type of noise was not identified) at $-10 \mathrm{~dB}$ signal-to-noise ratio the sentences are too easy and not useful diagnostically.

Giolas and Duffy (1973) examined the equivalency of the original sentences and a revised list of sentences (Harris, Haines, Kelsey, and Clack, 1961). The results of the experiment suggested that the sentence lists were not equivalent. However, the authors concluded that further research was warranted using the CID sentences in a different acoustic event. Rippy, Dancer, and Pittenger (1983) also evaluated the equivalency of the lists using normal hearing subjects and found the lists were not equivalent. However, Sims 
(1975) evaluated the equivalency of the lists using subjects with sensorineural hearing loss and found a high correlation among lists. In an analysis and revision of the Minimal Auditory Capabilities (MAC) Battery, which included the CID sentences, Owens, Kessler, Raggio, and Schubert (1985) found equivalent scores on lists 1,2 , and 4. As a result CID Everyday sentence lists 1 and 2 (i.e., A and B) were included in the revised MAC Battery. 
CHAPTER III

METHODS

This study investigated a measure of speech discrimination ability presented with competing cafeteria noise. The purpose of the investigation was twofold: (a) to establish normative data for the CID Everyday sentences, presented in cafeteria noise, discrimination test, and (b) to determine, in subjects with high frequency hearing loss, if the scores obtained on the speech discrimination test were significantly correlated to the subject's self-perception of hearing handicap as represented by the subject's score on the Hearing Handicap Inventory for Adults (HHIA).

\section{SUBJECTS}

Normal Hearing Subjects

Thirty-eight normal hearing subjects (male and female) were recruited to participate in the study. Subjects were predominately students; the age range was 19-46 years old. All normal hearing subjects passed a $15 \mathrm{~dB}$ HL pure tone air conduction screening test of octave frequencies between 250-8000 $\mathrm{Hz}$ (ANSI S3.6-1969). 
Hearing Impaired Subjects

Twelve male and female adult subjects were selected from patients evaluated at the Portland Veterans Administration Medical Center Audiology Clinic or Portland State University Audiology Clinic. Subjects had undergone, within 3 months prior to the investigation, an audiological evaluation consisting of pure tone and speech audiometric measures, immittance, and tone decay measures.

All hearing impaired subjects exhibited a bilateral symmetrical sensorineural hearing loss with thresholds not exceeding an average of $25 \mathrm{~dB}$ HL in frequencies between 250-2000 Hz, and elevated thresholds exceeding $25 \mathrm{~dB}$ $\mathrm{HL}$ in frequencies above $2000 \mathrm{~Hz}$. No subject demonstrated thresholds greater than $85 \mathrm{~dB} \mathrm{HL}$. Inter-ear threshold differences were no greater than $10 \mathrm{~dB}$. All subjects reported difficulty hearing in unaided situations where background noise was present. Speech discrimination scores, in quiet, were 90-100\% at 50 dB HL, typical conversation level.

Determination of sensorineural hearing loss was based on the following criteria:

1. Agreement, within $10 \mathrm{~dB}$, of air and bone conduction thresholds from 250 to $4000 \mathrm{~Hz}$.

2. Normal acoustic immittance findings: including tympanograms with peak pressure in the range of \pm 50 daPa, static admittance between 0.4 and $1.6 \mathrm{mmhos}$, and 
acoustic reflex thresholds of $100 \mathrm{~dB}$ SPL or less at 500 , 1000 , and $2000 \mathrm{~Hz}$.

3. The absence of retrocochlear signs, including abnormal tone decay, and abnormal reflex decay.

MATERIALS

The Hearing Handicap Inventory for Adults (HHIA) (Newman, et al. 1990) (Appendix A) was used to assess the self-perception of hearing difficulty for each hearing impaired subject.

The discrimination test consisted of a two-channel audio cassette tape recording of the CID sentences and cafeteria noise. A speech spectrum calibration signal, which was recorded at the beginning of the stimulus tape, allowed VU monitor adjustments to be made prior to the presentation. The CID sentences, presented by a general American male voice, were dubbed from an Auditec recording. The cafeteria noise was dubbed from a tape recording made in the Portland State University cafeteria.

Three versions of the tape were produced. CID sentence List $C$ appeared on each version to be used as a familiarization set. One of either List A, B, or D was used with List $C$ to complete the test tape (Appendix B). Each sentence list consisted of 10 sentences, comprised of 50 monosyllabic, phonetically balanced key words. A 5 second pause was inserted between each sentence to 
allow the subject time to respond. The response consisted of a verbal repetition of the sentence. Sentence list $A, B$, or D was randomly assigned to each subject.

\section{INSTRUMENTATION}

Testing was conducted in a double wall sound treated booth. Stimuli were presented to the subject binaurally, through TDH-39 headphones via a Beltone 2000 Clinical Audiometer by means of a Proton 740 cassette tape recorder. Calibration was conducted to meet ANSI S.36-1969 standards.

\section{PROCEDURES}

Normal Hearing Subjects

Subjects were seated in a double wall sound treated booth wearing binaural earphones. They were first screened for normal hearing; all passed a $15 \mathrm{~dB}$ HL air conduction screening test for octave frequencies between 250-8000 $\mathrm{Hz}$. Subjects were then read prepared instructions for responding to the sentence discrimination test (Appendix C). Subjects were asked to repeat the sentences they heard and encouraged to guess if necessary. The sentence test, mixed with the competing cafeteria noise, was presented to the subjects binaurally at $50 \mathrm{~dB} \mathrm{HL}$ with a 0 dB signal-to-noise ratio. Responses were recorded immediately by the investigator by marking each key word 
on the score sheet as correct or incorrect.

Hearing Impaired Subjects

Subjects were asked to complete the Hearing Handicap Inventory for Adults questionnaire immediately prior to the testing. Following completion of the questionnaire, each subject was asked if there were any items needing clarification. If so, clarification was provided and subjects then had the opportunity to change their response. Questionnaires were scored following the testing session. Subjects were seated in a double wall sound treated booth wearing binaural earphones. Subjects were then read prepared instructions for responding to the sentence discrimination test (Appendix C). They were asked to repeat the sentences they heard and encouraged to guess if necessary. The sentence test, mixed with competing cafeteria noise, was presented to the subjects binaurally at $50 \mathrm{~dB} \mathrm{HL}$ with a $0 \mathrm{~dB}$ signal-to-noise ratio. Responses were recorded immediately by the investigator by marking each key word on the score sheet as correct or incorrect. 
CHAPTER IV

RESULTS

DESCRIPTIVE DATA

Normal Hearing Subjects

Table 1 presented the raw performance data obtained from thirty-eight normal hearing subjects between the ages of 19-46 years. As seen in Table 2, summary of Perfomance Data of Normal Hearing Subjects, the mean overall age of the subjects was 28.1 years. Overall discrimination scores obtained, (combined Lists A, B, and D), ranged from 24-70\%, with a mean score of $47.4 \%$ and a standard deviation of $12.6 \%$. Scores obtained on the individual sentence lists $A, B$, and $D$ were similar: List $A$ had a range of scores between 24-66\%, a mean score of $50.18 \%$, and a standard deviation of $11.3 \%$; List $B$ scores ranged from 24-70\%, with a mean of $47.14 \%$ and a standard deviation of $13.2 \% ;$ and List $D$ scores ranged from 28-68\%, with a mean of $45.23 \%$, and a standard deviation of $11.9 \%$.

Data obtained from List $C$, the familiarization set, was included in the Tables, although it was not used in the data analysis. It was interesting to note that 
TABLE I

RAW PERFORMANCE DATA FOR NORMAL HEARING SUBJECTS

\begin{tabular}{|c|c|c|c|c|c|}
\hline \multirow[t]{2}{*}{ Subject \# } & \multirow[t]{2}{*}{ Age } & \multicolumn{2}{|r|}{ correct } & scores & \multirow[b]{2}{*}{ List $D$} \\
\hline & & List $C$ & List $A$ & List $B$ & \\
\hline 1 & 19 & .76 & & .62 & \\
\hline 2 & 23 & .54 & & .50 & \\
\hline 3 & 24 & .66 & & .58 & \\
\hline 4 & 25 & .66 & & .56 & \\
\hline 5 & 26 & .68 & & .52 & \\
\hline 6 & 26 & .60 & & .48 & \\
\hline 7 & 26 & .64 & & .24 & \\
\hline 8 & 27 & .56 & & .52 & \\
\hline 9 & 28 & .64 & & .44 & \\
\hline 10 & 28 & .48 & & .28 & \\
\hline 11 & 37 & .60 & & .70 & \\
\hline 12 & 45 & .54 & & .36 & \\
\hline 13 & 46 & .58 & & .28 & \\
\hline 14 & 46 & .86 & & .52 & \\
\hline 15 & 20 & .76 & .58 & & \\
\hline 16 & 22 & .78 & .56 & & \\
\hline 17 & 23 & .60 & .52 & & \\
\hline 18 & 23 & .62 & .66 & & \\
\hline 19 & 24 & .72 & .60 & & \\
\hline 20 & 24 & .64 & .24 & & \\
\hline 21 & 25 & .76 & .54 & & \\
\hline 22 & 27 & .66 & .42 & & \\
\hline 23 & 27 & .40 & .54 & & \\
\hline 24 & 29 & .60 & .50 & & \\
\hline 25 & 41 & .60 & .36 & & \\
\hline 26 & 22 & .36 & & & .52 \\
\hline 27 & 23 & .38 & & & .34 \\
\hline 28 & 23 & .52 & & & .42 \\
\hline 29 & 23 & .50 & & & .28 \\
\hline 30 & 24 & .34 & & & .40 \\
\hline 31 & 24 & .58 & & & .44 \\
\hline 32 & 25 & .70 & & & .46 \\
\hline 33 & 26 & .60 & & & .42 \\
\hline 34 & 28 & .60 & & & .54 \\
\hline 35 & 29 & .30 & & & .36 \\
\hline 36 & 38 & .50 & & & .34 \\
\hline 37 & 36 & .50 & & & .68 \\
\hline 38 & 38 & .70 & & & .68 \\
\hline
\end{tabular}


TABLE II

SUMMARY OF PEREORMANCE DATA OF NORMAL HEARING SUBJECTS

\begin{tabular}{|c|c|c|c|c|c|}
\hline Variable & $\begin{array}{c}\text { List } \\
A\end{array}$ & $\begin{array}{c}\text { List } \\
\text { B }\end{array}$ & $\begin{array}{c}\text { List } \\
D\end{array}$ & $\begin{array}{l}\text { List } \\
C *\end{array}$ & $\begin{array}{l}\text { List } \\
A, B, D\end{array}$ \\
\hline \multicolumn{6}{|l|}{ Age: } \\
\hline Range & $20-41$ & $19-46$ & $22-38$ & $19-46$ & $19-46$ \\
\hline Mean & 25.9 & 30.4 & 27.6 & 28.1 & 28.1 \\
\hline $\begin{array}{l}\text { Discrimination } \\
\text { Range: }\end{array}$ & $\begin{array}{l}\text { Scores: } \\
24-66\end{array}$ & $24-70$ & $28-68$ & $34-86$ & $24-70$ \\
\hline Mean: & 50.18 & 47.14 & 45.23 & 59.20 & 47.40 \\
\hline S.D.: & 11.3 & 13.2 & 11.9 & 12.5 & 12.6 \\
\hline
\end{tabular}

* List $C$ was the familiarization list given to all subjects.

the majority of subjects scored higher on List $c$. The mean score on List $C$ was 59.28 , and the standard deviation was 12.5\%. Possible explanations for this result could be the presence of an order effect (i.e., fatigue in background noise), or possibly because sentence list $C$ was simply not equivalent to the other lists. As discussed in the literature review, the CID sentences have been criticized for lack of equivalency between lists. This study, however, was not designed to look at order effect, therefore, it was not possible to interpret this result. 
Hearing Impaired Subjects

The raw data collected from twelve subjects with a high frequency hearing loss are presented in Table 3, and summarized in Table 4. The age range of the hearing-impaired subjects was 29-64 years, with a mean age of 46.1 years. The discrimination scores for combined Lists $A, B$, and $D$ ranged from 18-56\%, with a mean score of $38.7 \%$, and a standard deviation of $12.0 \%$. The sentence lists were not analyzed individually, as were the lists given to the normal hearing subjects, due to the small subject number.

A high frequency average threshold (HFA), expressed in decibels, was obtained for each subject by averaging the subject's air conduction thresholds at 3000,4000 , and $6000 \mathrm{~Hz}$ (Table 4). The HFA range was 36-81 dB HL, with a mean of $55.5 \mathrm{~dB}$, and a standard deviation of 11.25 dB. Also shown on Table 4 are the scores obtained on the Hearing Handicap Inventory for Adults (HHIA), including a total score and sub-scores for the social/situational and the emotional scales (A total score of 18 denotes a self-perceived handicap according to Ventry \& Weinstein, 1982). The range of total scores was 6-40, with a mean of 20, median of 14, and a standard deviation of 11 . The social sub-scale mean score was 11.3 , in a range of 6-20, with a median of 10 , and a standard deviation of 5.85. Scores for the emotional sub-score were from 
TABLE III

RAW PERFORMANCE DATA FOR HEARING IMPAIRED SUBJECTS

\begin{tabular}{|c|c|c|c|c|c|c|c|}
\hline$\overline{\text { subj \# }}$ & Age & $\begin{array}{l}\mathrm{g} \\
\mathrm{C}\end{array}$ & $\begin{array}{c}\text { Correct } \\
A\end{array}$ & $\begin{array}{l}\mathrm{SC} \\
\mathrm{B}\end{array}$ & $\begin{array}{r}\text { es } \\
\text { D }\end{array}$ & $\overline{\mathrm{HFA}}$ & $\begin{array}{c}\text { HHIA } \\
\text { Soc/Emo }\end{array}$ \\
\hline$\overline{I-1}$ & 38 & .58 & .22 & & & 58 & $\begin{array}{c}24 \\
10 / 14\end{array}$ \\
\hline$I-2$ & 64 & .26 & .34 & & & 68 & $\begin{array}{c}34 \\
18 / 16\end{array}$ \\
\hline$I-3$ & 50 & .62 & .50 & & & 57 & $\begin{array}{l}10 \\
8 / 2\end{array}$ \\
\hline$I-4$ & 52 & .42 & .48 & & & 51 & $\begin{array}{l}6 \\
6 / 0 .\end{array}$ \\
\hline$I-5$ & 29 & .72 & & .56 & & 48 & $\begin{array}{l}36 \\
20 / 16\end{array}$ \\
\hline$I-6$ & 50 & .66 & & .44 & & 81 & $\begin{array}{l}10 \\
10 / 0\end{array}$ \\
\hline$I-7$ & 64 & .50 & & .34 & & 61 & $\begin{array}{l}26 \\
12 / 14\end{array}$ \\
\hline$I-8$ & 41 & .34 & & .18 & & 42 & $\begin{array}{l}14 \\
8 / 6\end{array}$ \\
\hline$I-9$ & 45 & .44 & & & .52 & 50 & $\begin{array}{l}14 \\
8 / 6\end{array}$ \\
\hline$I-10$ & 52 & .38 & & & .30 & 56 & $\begin{array}{l}40 \\
18 / 22\end{array}$ \\
\hline$I-11$ & 37 & .48 & & & .42 & 36 & $\begin{array}{l}12 \\
8 / 4\end{array}$ \\
\hline$I-12$ & 32 & .72 & & & .34 & 58 & $\begin{array}{l}14 \\
10 / 4\end{array}$ \\
\hline
\end{tabular}


0-22, with a mean of 8.7 , median of 6.0 , and a standard deviation of 7.03 .

\section{TABLE IV}

COMPARISON OF SUMMARIZED PERFORMANCE DATA FOR BOTH GROUPS OF SUBJECTS

\begin{tabular}{|c|c|c|}
\hline $\begin{array}{l}\text { Normal Hearing Subjects } \\
\mathrm{N}=38\end{array}$ & $\begin{array}{l}\text { Hearing } \\
\mathrm{N}=12\end{array}$ & Impaired subjects \\
\hline 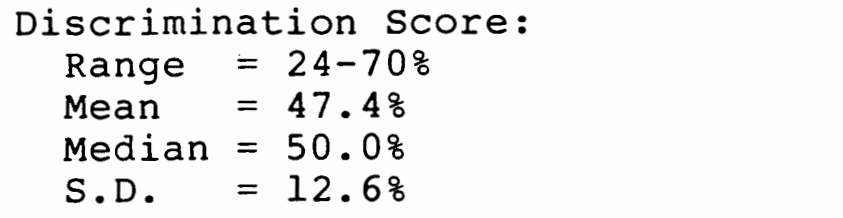 & $\begin{array}{l}\text { Range } \\
\text { Mean } \\
\text { Median } \\
\text { S.D. }\end{array}$ & $\begin{array}{l}=18-568 \\
=38.78 \\
=38.08 \\
=12.08\end{array}$ \\
\hline HFA (High frequency average $3,4,6$ & $\begin{array}{l}\mathrm{KHz} \text { ): } \\
\quad \text { Range } \\
\text { Mean } \\
\text { Median } \\
\text { S.D. }\end{array}$ & $\begin{array}{l}=36-81 \mathrm{~dB} \\
=55.50 \mathrm{~dB} \\
=56.50 \mathrm{~dB} \\
=11.25 \mathrm{~dB}\end{array}$ \\
\hline $\begin{array}{l}\text { HHIA (Hearing Handicap Inventory- } \\
\text { Total Score: } \\
\text { Social sub scale: } \\
\text { Emotional sub scale: }\end{array}$ & $\begin{array}{l}\text { Adults): } \\
\text { Range } \\
\text { Mean } \\
\text { Median } \\
\text { S.D. } \\
\text { Range } \\
\text { Mean } \\
\text { Median } \\
\text { S.D. } \\
\text { Range } \\
\text { Mean } \\
\text { Median } \\
\text { S.D. }\end{array}$ & $\begin{array}{l}=6-40 \\
=20 \\
=14 \\
=11.0 \\
=6-20 \\
=11.3 \\
=10 \\
=5.85 \\
=0-22 \\
=8.70 \\
=6.00 \\
=7.03\end{array}$ \\
\hline
\end{tabular}

DATA ANALYSIS

Exploratory data analysis performed on discrimination scores of all 50 subjects failed to disprove normality of the data distribution for the variable "score" on 
the sentence tests. Box plot tails were fairly equal in length (Figure 1 ) and the mean and median scores of 45.28 and 47.0 were close. Therefore, further statistical analysis was performed based on the assumption of normally distributed data. The plot of residuals vs fits, for hearing impaired subjects only, showed no evidence of non-normality (Figure 2); however, as the data set for the hearing impaired subjects was relatively small, it was inconclusive whether the data were normally distributed for the hearing impaired subjects alone. Nevertheless, further analysis was based upon the assumption of normality.

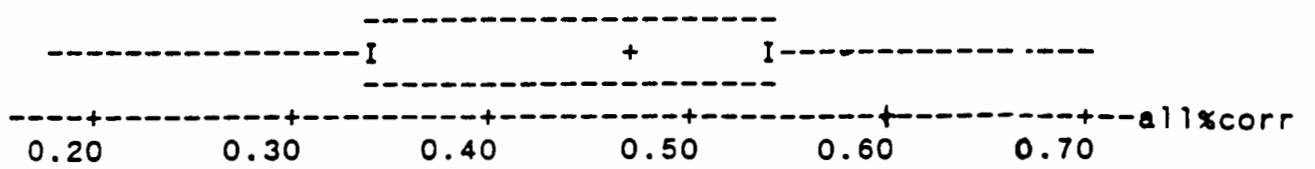

Figure 1. Box plot of discrimination scores for all 50 subjects.

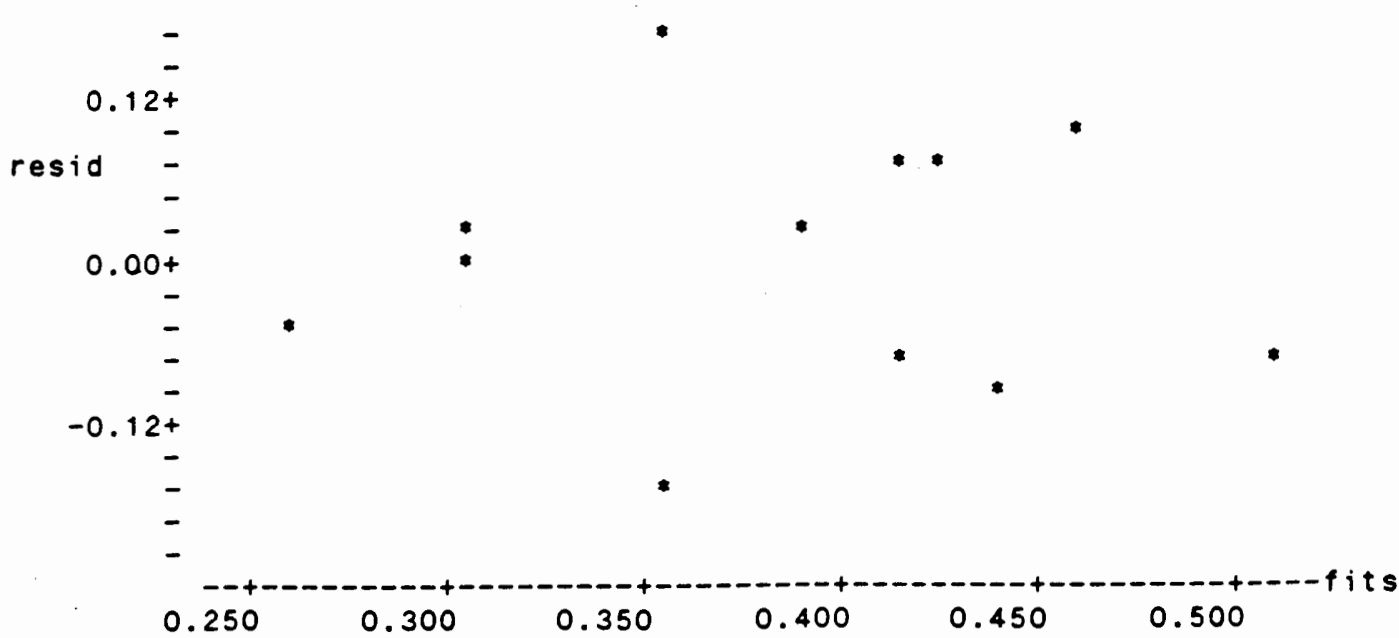

Figure 2. Plot of residuals vs fits for hearing impaired subjects. 
In order to determine if the discrimination scores obtained by the normal hearing subjects and the hearing impaired subjects were significantly different, a twotailed t-test was used to examine the significance between means. This analysis indicated that the mean discrimination score of the hearing impaired subjects was significantly lower than that of the normal hearing subjects $(p=0.04)$. To determine if there was a relationship between the scores obtained by the hearing impaired subjects on the Hearing Handicap Inventory and the scores obtained on the discrimination test, regression analysis was performed. A relationship was found between the HHIA Emotional sub-score, the Social sub-score and the discrimination score. However, the correlation was only moderate $(p=0.133, r=0.602)$ and the confidence level did not meet the 0.05 criteria for significance selected in the study design.

Additional evaluation of the data supported findings by other investigators cited in the literature review. The equivalency of the CID sentence lists $A, B$, and D, which was reported by Owens, et al. (1983), was also found in this study by correlation co-efficients of -0.50 between the lists. 
CHAPTER V

\section{DISCUSSIONS AND CONCLUSIONS}

The investigator's interest in this study was motivated by the clinical desire to both quantify and validate the experience of difficulty understanding speech in background noise reported by clients who exhibit a hearing loss in the higher frequencies only. It was speculated that this test would present a speech discrimination task that was more realistic for evaluating the speech discrimination ability of those with high frequency hearing loss than that which is typically used (i.e., phonetically balanced words presented in quiet.) The person with a high frequency hearing loss will typically score in the normal range on a $\mathrm{PB}$ word discrimination test.

The purpose of the study was to establish normative data, and to investigate the relationship between the speech discrimination ability of the subjects and the self-assessed real life difficulty reported by these subjects. Discrimination scores derived from the CID Everyday Sentences presented in cafeteria noise, were compared with scores obtained on the Hearing Handicap Inventory for Adults (HHIA). 
It was hypothesized that (a) there would be a significant difference between the speech discrimination scores of the hearing impaired subjects and those subjects with normal hearing, and (b) that there would be a correlation between the hearing impaired subjects' discrimination scores and their scores on the HHIA.

The data analysis in this investigation supported the first hypothesis, but not the second. A statistically significant difference between the discrimination scores of the two subject groups was noted. Although some correlation was found between the scores on the discrimination test and the scores on the self-assessment questionnaire, it was considered weak to moderate and did not meet the criteria for statistical significance. The subjective response of the subjects to this experimental task was noteworthy. Many normal hearing subjects volunteered that the test was surprisingly difficult, and complained that the speaker was mumbling. on the other hand, the hearing impaired subjects reported that the task was very much like their experience when they were in a restaurant or in a room with several people talking. These responses could suggest that at least from a subjective perspective this test may reflect an everyday listening experience for those with high-frequency hearing loss.

The data analysis in this investigation revealed considerable variability in the discrimination scores 
of both the normal hearing and hearing impaired subjects, although the scores were significantly lower for the hearing impaired. This finding of increased variability of response in background noise was consistent with findings well established in hearing science literature for both normal hearing and hearing impaired subjects.

\section{IMPLICATIONS FOR FURTHER RESEARCH}

The variability of response on the discrimination test, as well as the retest reliability, could use further exploration. The present investigation has validated the equivalency of three different CID Sentence lists, these lists could now be used for test/retest comparisons, as well as experiments using different signal-to-noise ratio comparisons. Additionally the subject numbers need to be increased for both subject groups.

Another issue is the materials used. In designing the study it was considered whether to produce a recording of the sentences using a male speaker who was trained in public speaking, however the Auditec tape was selected because it is easily available for other clinicians to purchase. Normal hearing subjects complained about the voice quality of the speaker on the Auditek tape, and their discrimination scores were lower than expected. This response raises the question regarding the effect of the speaker's voice versus the effect of the noise. 
In a repeat of the study it would be important to use a different recording where in quiet the speaker sounds perfectly clear to normal hearing subjects.

A study would be useful which investigates whether there is an adaptation effect or fatigue effect on discrimination ability in background noise. In the present study List $C$ was given to all subjects as a warm up list. It was thought that subjects would perform better on the second list of words after adapting to the noise. However, the opposite results were obtained, almost all subjects performed worse on the second set of sentences. Some subjects reported that they were so tired by the second set that they "sort of gave up". In order to determine if there is some sort of fatiguing effect when listening in background noise the sentence lists which were validated as equivalent could be randomly presented.

\section{CONCLUSIONS}

This study showed the speech discrimination testing procedure to have potential merit for quantifying the handicap produced by a high frequency hearing loss. With further research, it may be possible to develop, from these materials, a quick and easily administered speech discrimination test in noise which is efficient enough for clinical use. 
REFERENCES

Abel, S.M., Krever, E.M., \& Alberti, P.W. (1990). Auditory detection, discrimination and speech processing in aging, noise-sensitive and hearing-impaired listeners. Scandinavian Audiology, 19, 43-54.

Bess, F.H., \& Townsend, T.H. (1977). Word discrimination of listeners with flat sensorineural hearing losses. Journal of Speech Hearing Disorders, 42, 232-237.

Cooper, J.C., \& Cutts, B.P. (1971). Speech discrimination in noise. Journal of Speech and Hearing Research, $14,332-337$.

Davis, H., \& Silverman, S. (1978). Hearing and Deafness (5th Ed). New York. Holt, Rinehart, and Winston.

Davis J., \& Hardick, E. (1981). Rehabilitative Audiology for Children and Adults. New York. Wiley.

Garstecki, D.C. (1980). Alternative approaches to measuring speech discrimination efficiency. In Rupp, R.R. \& Stockdell, Sr., K.G. (Ed.), speech Protocols in Audiology. New York. Grune \& Stratton.

Giolas, T.G. (1982). Hearing Handicapped Adults. New Jersey. Prentice-Hall.

Giolas, T.G., \& Duffy, J.R. (1973). Equivalency of CID and Revised CID Sentence Lists. Journal of Speech and Hearing Research, 16, 549-555.

Giolas, T.G. (1966). Comparative intelligibility scores of sentence lists and continuous discourse. Journal of Auditory Research, $6,31-38$.

Harris, J.D., Haines, H.L., Kelsey, A.P., \& Clack, T.D. (1961). The relation between speech intelligibility and electroacoustic characteristics of low fidelity circuitry. Journal of Auditory Research, 1, 357-381.

Kalikow, D.N., \& Stevens, K.N. (1977). Development of a test of speech intelligibility in noise using sentence materials with controlled word predictability. Journal Acoustical Society of America, 61(5), 1337-1351. 
Newby, H.A., \& Popelka, G.R. (1985). Audiology (5th Ed). Englewood Cliffs, N.J. Prentice-Hall.

Newman, C.W., Weinstein, B.E., Jacobson, G.P., \& Hug, G.A. (1990). The Hearing Handicap Inventory for Adults: psychometric adequacy and audiometric correlates. Ear and Hearing, 11(6), 430-433.

Olsen, W.O., \& Matkin, N.D. (1979). Speech audiometry. In Rintelman, W.F. (Ed.), Hearing Assessment. Baltimore. University Park Press.

Owens, E., Kessler, D.K., Raggio, M.W., \& Schubert, E.D. (1985). Analysis and revision of the Minimal Auditory Capabilities (MAC) Battery. Ear and Hearing, 6(6), 280-290.

Pekkarinen, E., Salmivalli, A., \& Suonpaa, J. (1990). Effect of noise on word discrimination by subjects with impaired Hearing, compared with those with normal hearing. Scandinavian Audiology, 19, 31-36.

Rippy, J.V., Dancer, J.E., \& Pittenger, J.B. (1983). List Equivalency of the CID Everyday Sentences (Harris Revision) under three signal-to-noise ratios. Ear and Hearing, 4(5), 251-254.

Silverman, S.R., \& Hirsh, I.J. (1955). Problems related to the use of speech in clinical audiometry. Annals of Otorhinolarygology, 64, 1234-1244.

Sims, D.G. (1975). The validation of the CID Everyday Sentence Test for use with the severely hearing impaired. Journal of the Academy of Rehabilitative Audiology, 8, 16-22.

Stockdell, Sr., K.G. (1980). Classical approaches for measuring discrimination efficiency via word lists. In Rupp, R.R., \& Stockdell, Sr. K.G. (Ed.), Speech Protocals in Audiology. New York. Grune \& Stratton.

Suter, A.H. (1985). Speech recognition in noise by individuals with mild sensorineural hearing impairments. Journal Acoustical Society of America, 78, 887-900.

Ventry I.M., \& Weinstein, B.E. (1982). The Hearing Handicap Inventory for the Elderly: a new tool. Ear and Hearing, 3(3), 128-134.

Weinstein, B.E., \& Ventry, I.M. (1983). Audiometric correlates of the Hearing Handicap Inventory For the Elderly. Journal of Speech and Hearing Disorders, 48, 379-384. 
APPENDIX A

HHIA SELF-ASSESSMENT QUESTIONNAIRE 
APPENDIX A

Self-Assessment Questionnaire

Bearing Questionnaire - HHIA

Name :

Date:

Instructions: The purpose of this questionnaire is to identify the problems your hearing loss may be causing you. Answer yes, sometimes, or no by placing a check mark in the appropriate space. Please answer all questions. If you use a hearing aid, answer the way you hear without the aid.

Yes Some- No
Times

1) Does a hearing problem cause you to use the phone less often than you would like?

2) Does a hearing problem cause you to feel embarrassed when meeting new people?

3 ) Does a hearing problem cause you to avoid groups of people?

4) Does a hearing problem make you irritable?

5) Does a hearing problem cause you to feel frustrated when talking to members of your family?

6) Does a hearing problem cause you difficulty when attending a party?

7) Does a hearing problem cause you to feel frustrated when talking to coworkers, clients, or customers?

8) Does a hearing problem cause you difficulty in the movies or theater?

9) Do you feel handicapped by a hearing problem?

10) Does a hearing problem cause you difficulty when visiting friends, relatives, or neighbors?

11) Does a hearing problem cause you difficulty hearing/understanding coworkers, clients or customers?

12) Does a hearing problem cause you to be nervous?

13) Does a hearing problem cause you to visit friends, relatives, or neighbors less often than you would like?

14) Does a hearing problem cause you to have arguments with your family nembers? 


\section{APPENDIX A}

SELF-ASSESSMENT QUESTIONNAIRE

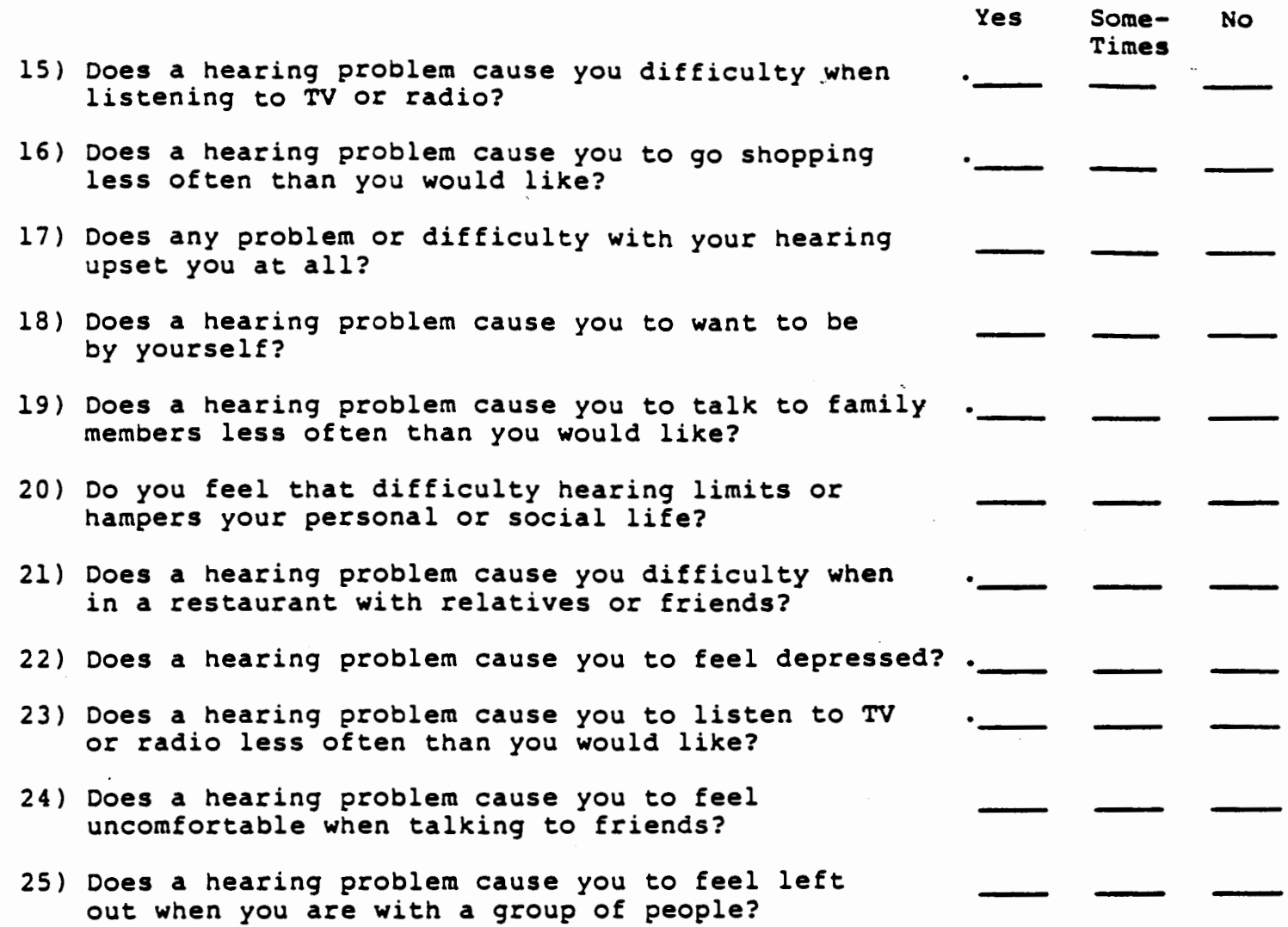

For clinic use only:

Score:

S. 
APPENDIX B

CID EVERYDAY SPEECH SENTENCES 
APPENDIX B

CID EVERYDAY SENTENCES

LIST A

1. Walking's my favorite exercise.

2. Here's a nice quiet place to rest.

3. Ourjanitor sweeps the floors every night.

4. It would be much easier if everyone would help.

5. Good Morning?

6. Open your window before you go to bed:

7. Do you think that she should stay out so late?

8. How do you feel about changing the time when we begin work?

9. Here we go.

10. Move out of the way!

\section{LIST B}

1. The water's too cold for swiming.

2. Why should I get up so early in the morning?

3. Here are your shoes.

4. It's raining.

5. Where are you going?

6. Come here when I call you!

7. Don't try to get out of it this time:

8. Should we let little children go to the movies by themselves?

9. There isn, t enough paint to finish the room.

10. Do you want an egg for breakfast?

\section{LIST C}

1. Everybody should brush his teeth after meals.

2. Everything's all right.

3. Don't use up 311 the paper when you write your letter.

4. That's right.

5. People ought to see a doctor once a year.

6. Those windows are so dirty I can't see anything outside.

7. Pass the bread and butter piease!

8. Don't forget to pay your bill before the first of the month.

9. Don't let the dog out of the house!

10. There's a good ballgame this afternoon.

1. It's time to go.

2. If you don't want these old magazines, throw them out.

3. Do you want to wash up?

4. It's a $\overline{\text { real }}$ dark night so watch your driving.

5. I'll carry the package for you.

6. Did you forget to shut off the water?

7. Fishing in a mountain strean is my idea of a good time.

8. Fathers spend more time with their children than they used to.

9. Be careful not to break your glasses!

10. I $\mathrm{m}$ sorry. 
APPENDIX C

SUBJECT INSTRUCTIONS 
APPENDIX C

SUBJECT INSTRUCTIONS FOR SENTENCES IN NOISE

The next procedure will be presented by taped voice.

You will first hear, in both ears, noise that sounds much like that you might hear in a restaurant. This noise will continue throughout the procedure.

Next you will hear a male voice presenting a list of sentences. There will be two groups of ten sentences. Each group of sentences will be introduced by the words "List A" or "List C", etc. These words will cue you to listen carefully for the coming sentences.

Your task is to repeat back the sentences. There will be a pause following each sentence to allow you time to do so. Some sentences will be long and others shorter. If you are not sure of what you are hearing, please take a guess and repeat as much as you are able. 